\title{
CFTR does it again: control of insulin secretion
}

\author{
MUALLEM Shmuel \\ Epithelial Signaling and Transport Section, National Institutes of Health/NIDCR, Bethesda, MD 20892, USA
}

Received August 11, 2014; accepted August 15, 2014; published online August 23, 2014

Citation: Muallem S. CFTR does it again: control of insulin secretion. Sci China Life Sci, 2014, 57: 1046, doi: 10.1007/s11427-014-4741-z

A major breakthrough in understanding diabetes mellitus, especially in the disease cystic fibrosis (CF) was made recently by the group of Dr. Hsiao Chang Chan from the Epithelial Cell Biology Research Center, Key Laboratory of Regenerative Medicine of Ministry of Education of China, the Chinese University of Hong Kong, Hong Kong, China. Their studies were reported recently in Guo et al. [1].

$\mathrm{CF}$ is caused by mutations in the $\mathrm{Cl}^{-}$channel, Cystic Fibrosis Transmembrane conductance Regulator (CFTR). Most often diabetes mellitus is a result of impaired glucose tolerance, which is common complications of CF. However, although we know quite well how glucose causes insulin secretion to control body energetics, we do not know how impaired CFTR activity leads to cystic fibrosis-related diabetes (CFRD) and potential role of CFTR in other forms of diabetes.

Glucose causes insulin secretion by entering into $\beta$ cells in the islands of Langerhans. In $\beta$ cells, glucose is converted to ATP, and the increased ATP inhibits an inward rectifying $\mathrm{K}^{+}$channel to depolarize the cells. The depolarization activates a voltage-gated $\mathrm{Ca}^{2+}$ channel to allow $\mathrm{Ca}^{2+}$ entry into the $\beta$ cells, resulting in an increase in cytoplasmic $\mathrm{Ca}^{2+}$. The $\mathrm{Ca}^{2+}$ then triggers the exocytosis of granules containing the insulin. Hence, control and changes in the membrane potential are key in determining insulin secretion and energetic control. Hypothesizing that as a $\mathrm{Cl}^{-}$channel, CFTR may regulate $\beta$ cell membrane potential and impaired CFTR activity may lead to impaired insulin secretion, Chan et al. set to test this hypothesis.
Dr. Chan and colleagues first showed that $\beta$ cells express CFTR and CFTR is activated by glucose to increase $\mathrm{Cl}^{-}$ current and control intracellular $\mathrm{Cl}^{-}$concentration in these cells. Most notably, the most common human mutation that causes CF, $\triangle$ F508, when introduced in mice, caused hyperpolarization of the $\beta$ cell membrane potential. Moreover, manipulation of CFTR activity showed that CFTR $\mathrm{Cl}^{-}$current was required to prevent hyperpolarization of the membrane potential. Absence of CFTR activity was sufficient to reduce the depolarization caused by glucose-mediated inhibition of the ATP-regulated $\mathrm{K}^{+}$channels. Thus, in the absence of CFTR activity, the glucose-evoked $\beta$ cell action potentials were reduced and consequently insulin secretion.

As expected from the findings with $\beta$ cells, mice with mutated CFTR have lower insulin levels than wild-type mice, and show reduced response to glucose. Most excitedly, Dr. Chan and co-workers showed that treatment of the mice with drugs developed to treat $\mathrm{CF}$ also corrected insulin secretion. These drugs are already in the clinic or are being tested with patients, thus they are very promising therapy in CF patients and may be even used in other forms of diabetes to boost insulin secretion.

1 Guo JH, Chen H, Ruan YC, Zhang XL, Zhang XH, Fok KL, Tsang LL, Yu MK, Huang WQ, Sun X, Chung YW, Jiang X, Sohma Y, Chan HC. Glucose-induced electric activities and insulin secretion in pancreatic islet $\beta$-cells are modulated by CFTR. Nat Commun, 2014, 5: 4420

Open Access This article is distributed under the terms of the Creative Commons Attribution License which permits any use, distribution, and reproduction in any medium, provided the original author(s) and source are credited.

email: shmuel.muallem@nih.gov 